\title{
A Dual-Band Rectangular CPW Folded Slot Antenna for GNSS Applications
}

\author{
Abdelati REHA ${ }^{1}$, Marouane BOUCHOUIRBAT ${ }^{2}$ \\ Assistant professor, Dept. of Telecommunications, IGA-Marrakech, Marrakech, Morocco ${ }^{1}$ \\ Assistant professor, Dept. of Electronics, IGA-Marrakech, Marrakech, Morocco ${ }^{2}$
}

\begin{abstract}
In this paper, a dual-band rectangular CPW folded slot antenna is studied for the Global Navigation Satellite Systems (GNSS) applications. The antenna operates for all the bands of the GNSS Systems (L1-L2-L5-E5-E6G1-G2) and its maximum gain varies between $0.2 \mathrm{~dB}$ and $2.9 \mathrm{~dB}$ in the band of $1200-1800 \mathrm{MHz}$. The antenna is simulated with "FEKO 6.3", manufactured and measured with "FeedBack Antenna Lab 52-200".
\end{abstract}

KEYWORDS: Dual-band Antenna, Folded Slot Antenna, GALILEO, GLONASS, GNSS, GPS, Slotted Antenna.

\section{I.INTRODUCTION}

With the deployment of several GNSS such as GPS, GLONASS and GALILEO, and with the growing need to develop systems capable of receiving signals from any GNSS, it is necessary to design a compact antenna operating in all frequency bands for at least the three major systems: GPS, GALILEO and GLONASS.

As shown in Fig1, the GPS satellites transmit signals using three different bands centred on the frequencies:

L1: $1575.42 \mathrm{MHz}, \mathrm{L} 2: 1$ 227,60 MHz, L5: 1 176,45 MHz.

The GALILEO satellites transmit signals using three different bands centred on the frequencies:

L1: $1575.42 \mathrm{MHz}$, E6: $1278.75 \mathrm{MHz}$, E5: $1191.79 \mathrm{MHz}$

And the GLONASS satellites transmit signals using two different bands centred on the frequencies:

G1: $1248 \mathrm{MHz}, \mathrm{G} 2: 1600 \mathrm{MHz}$ [1]-[3].

One of the ways to design a broadband and multiband antenna is to set-up slots on the radiation elements [4], [5].

In this paper, a novel dual-band rectangular CPW folded slot antenna is presented. This antenna is designed for operating in all the bands of the three GNSS Systems GPS, GALILEO and GLONASS. Also the antenna is simulated by "FEKO 6.3" [6], manufactured and measured by "Feedback Antenna Lab 52-200".

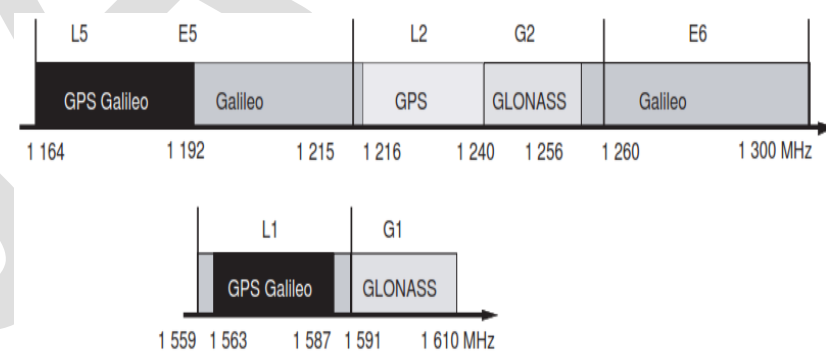

Fig.1 the frequencies bands used for the GNSS systems

\section{LITEARTURE SURVEY}

With the proliferation and miniaturization of telecommunications systems and their integration in restricted environments, such as Smart-phones, tablets, cars, airplanes, and other embedded systems. The design of compact multi-bands and Ultra Wide Band (UWB) antennas becomes a necessity. For designing this kind of antennas, several techniques are used such as using fractal geometries or adding slots to the radiating elements [7]-[10]. 


\section{ANTENNA GEOMETRY}

The geometry of the proposed antenna is shown in fig2. The antenna is printed on a FR4 dielectric substrate of relative permittivity $\varepsilon_{\mathrm{r}}=4.3$, thickness $\mathrm{H}=1.6 \mathrm{~mm}$, loss tangent $=0.025$ and fed by a $50 \Omega \mathrm{CPW}$ transmission line with a signal strip width $\mathrm{W}_{\mathrm{f}}$ and a gap distance $\mathrm{G}$ between the signal strip and the ground plane. Several studies have used this mode of feeding because it's one of the techniques to increase the Bandwidth of the antenna [10]-[14].
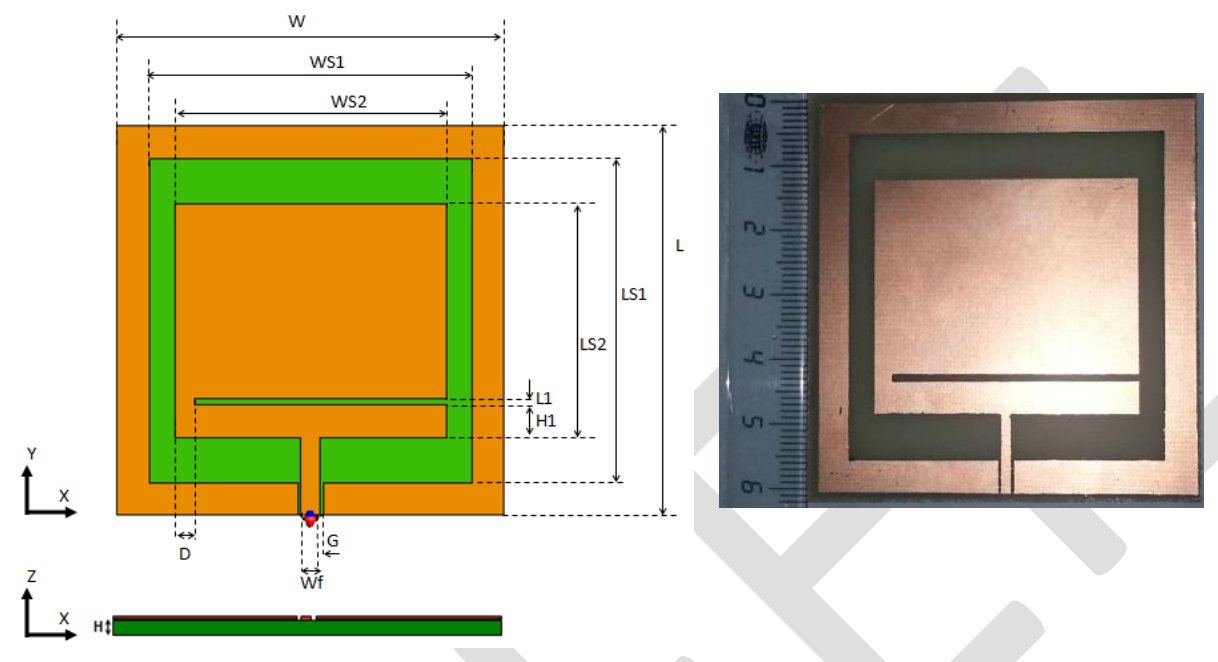

Fig. 2 Geometry of the proposed antenna

The parameters of the antenna are: $\mathrm{W}=60 \mathrm{~mm}, \mathrm{~W}_{\mathrm{s} 1}=50 \mathrm{~mm}, \mathrm{~W}_{\mathrm{s} 2}=42 \mathrm{~mm}, \mathrm{~L}=60 \mathrm{~mm}, \mathrm{~L}_{\mathrm{s} 1}=50 \mathrm{~mm}, \mathrm{~L}_{\mathrm{s} 2}=36 \mathrm{~mm}, \mathrm{G}=0.5 \mathrm{~mm}$, $\mathrm{W}_{\mathrm{f}}=1.5 \mathrm{~mm}, \mathrm{D}=3 \mathrm{~mm}, \mathrm{~L}_{1}=1 \mathrm{~mm}$ and $\mathrm{H}=1.6 \mathrm{~mm}$.

\section{A. The patch antenna}

\section{DESIGN OF THE ANTENNA}

It is very important for the simulation by FEKO to estimate the resonant frequency to have an idea about the dimensions of the patch antenna.

Based on the TLM (Transmission Line Model), the resonant frequency $\left(\mathrm{F}_{\mathrm{res}}\right)$ of the patch antenna is approximated by the equation (1)[15]

With: $\quad c=3.10^{8} \mathrm{~ms}^{-1}$

$$
F_{\text {res }}=\frac{c}{2 W \sqrt{\frac{\varepsilon_{r}+1}{2}}}
$$

$\varepsilon_{\mathrm{r}}$ : the relative permittivity of the dielectric

W: the width of the patch

For example, if $\mathrm{f}_{\mathrm{res}}=2.2 \mathrm{GHz}$ and $\varepsilon_{\mathrm{r}}=4.3$, the width of the patch is $42 \mathrm{~mm}$. 


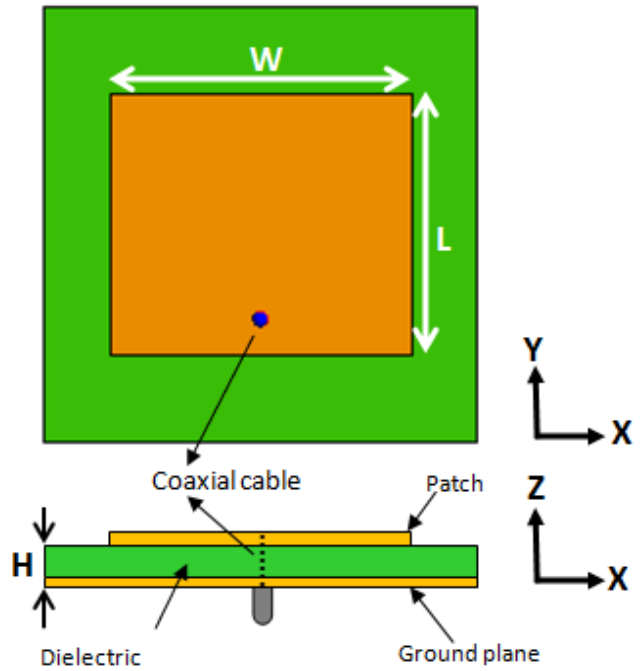

Fig. 3 the patch antenna

Using the FEKO software to design a patch antenna with the following parameters: $W=42 \mathrm{~mm}, \mathrm{~L}=36 \mathrm{~mm}$, and $\mathrm{H}=1.6 \mathrm{~mm}$ (Fig.3)

The $S_{11}$ characteristic of the simulated structure is depicted in Fig4. From the results, it is evident that the antenna operates at the frequency $1849 \mathrm{MHz}$ whose $\mathrm{S}_{11}=-11.46 \mathrm{~dB}$ with a bandwidth $(-10 \mathrm{~dB})$ of $38 \mathrm{MHz}$. We observe that this value is different for the resonant frequency given by the TLM model because the FEKO software is based on a full wave method: the Method of the Moment (MoM). The full wave methods like the MoM, the Finite Integral Technique (FIT), and Finite Element Method (FEM) are more accurate compared to the TLM method[7] [12]

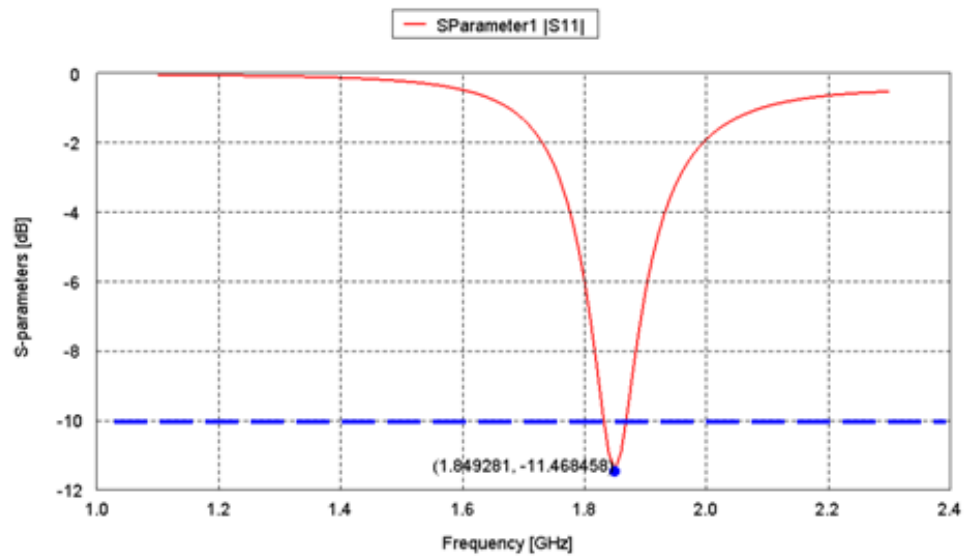

Fig. 4 Simulated $S_{11}$ versus frequency graph of the patch antenna.

\section{B. Feeding methods of the patch antenna}

There are many configurations that can be used to feed a patch antenna. In this section we compare the effect of three feeding methods: coaxial probe (Fig.5 - case1), Microstrip line with the ground plane in the reverse face of the patch (Fig.5 - case2), and Microstrip line with the ground plane in the same face of the patch (Fig.5 - case3). 
International Journal of Advanced Research in Electrical, Electronics and Instrumentation Engineering

(An ISO 3297: 2007 Certified Organization)

\section{Vol. 3, Issue 8, August 2014}

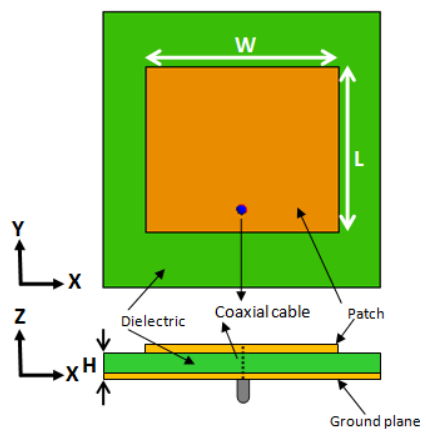

(a) Case1

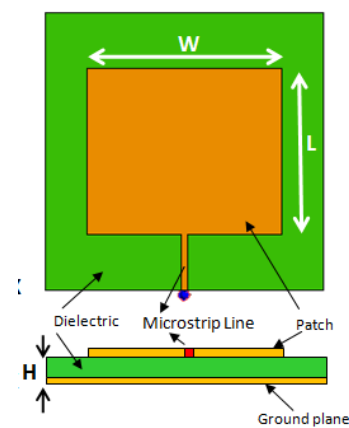

(b) Case2

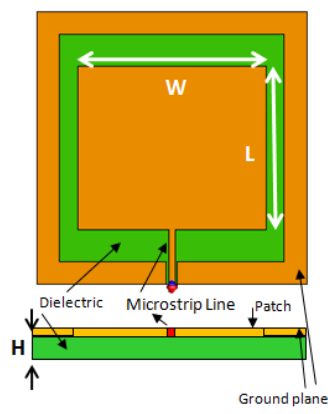

(c) Case3

Fig. 5 the different feeding methods

We note that for the case 3 (Fig.6) the resonant frequency is lower than for the case 1 and 2. This is an important advantage to design a miniaturized antenna without increasing its volume and surface. We note also that the bandwidth is larger than those of case 1 and case 2 .

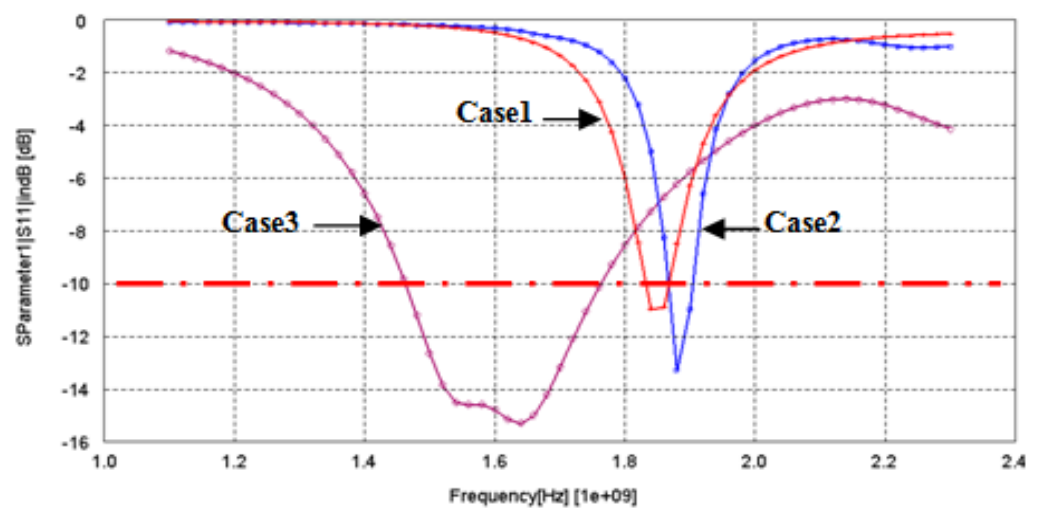

Fig. 6 Simulated $S_{11}$ versus frequency of the three cases of the patch antenna

\section{The choice of $\mathbf{H 1}$}

To generate multi-resonance antenna, we setup a slot on the patch antenna as shown in fig.2. The H1 parameter is the position of this slot.

We will vary the $\mathrm{H} 1$ parameter from 2 to $5 \mathrm{~mm}$ with step of $1 \mathrm{~mm}$. we obtain the result shown in (Fig.7). We can consider that the $\mathrm{H} 1=2 \mathrm{~mm}$ is the most appropriate for the GNSS applications; the table 1 shows the detail of the result.

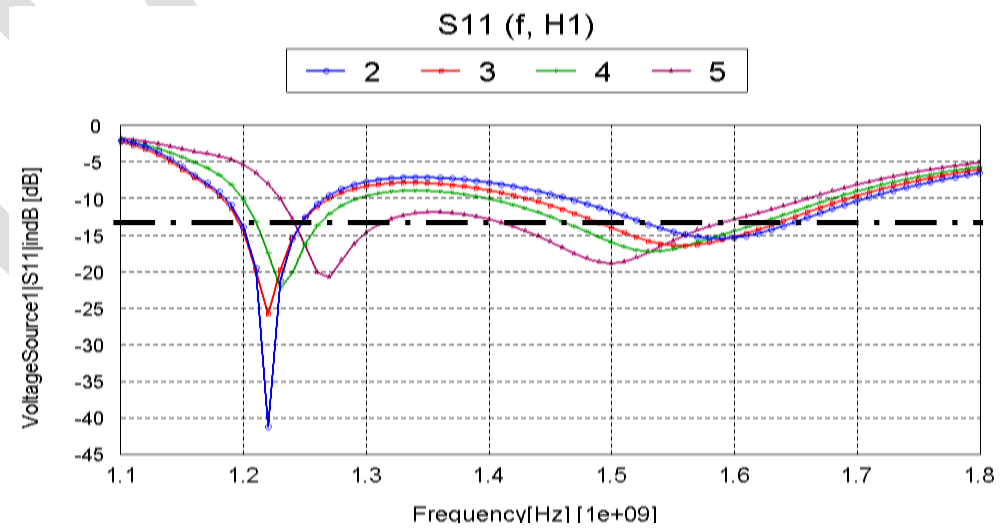

Fig. 7 Parametric Simulated $S_{11}$ versus frequency of the antenna 
International Journal of Advanced Research in Electrical, Electronics and Instrumentation Engineering

(An ISO 3297: 2007 Certified Organization)

\section{Vol. 3, Issue 8, August 2014}

Table 1: the bands covered by the antenna for different values of $\mathrm{H} 1$

\begin{tabular}{|c|c|c|c|}
\hline H1 & Bandwidth & Bands & Systems \\
\hline 2 & $1170-$ & L5/E5/L2/E6/G1 & GPS(L1/L2/L5) \\
& 1280 & ----- & GALILEO(L1/E6/E5) \\
& ---- & L1/G2 & GLONASS(G1/G2) \\
& $1450-1710$ & & \\
\hline 3 & $1165-$ & L5/E5/L2/E6/G1 & GPS(L1/L2/L5) \\
& 1285 & ----- & GALILEO(L1/E6/E5) \\
& ---- & L1/G2 & GLONASS(G1/G2) \\
& $1420-1700$ & & GPS(L1/L2) \\
\hline 4 & $1197-$ & L2/E6/G1 & GALILEO(L1/E6) \\
& 1296 & ----- & GLONASS(G1/G2) \\
& ----- & L1/G2 & GPS(L1/L2) \\
& $1400-1680$ & & GALILEO(L1/E6) \\
\hline 5 & $1226-$ & L2/E6/G1/L1/G2 & GLONASS(G1/G2) \\
\hline
\end{tabular}

We note that for $\mathrm{H} 1=2 \mathrm{~mm}$ and $\mathrm{H} 1=3 \mathrm{~mm}$ the antenna operates for all the bands of all the GNSS Systems.

\section{RESULTS AND DISCUSSION}

First we simulated the patch antenna with and without the slot. The figure (Fig8) shows that the set up of the slot provides a new resonance frequency.

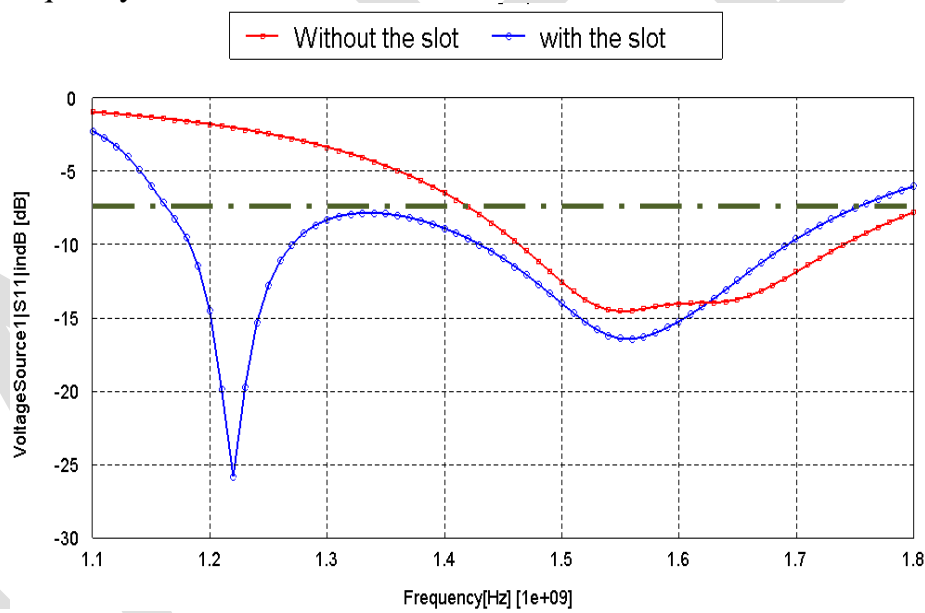

Fig .8 Simulated $\mathrm{S}_{11}$ versus frequency of the antennas (with/without the slot)

After that, we manufactured the antenna on a PCB (Printed Circuit Board) and we measured the $\mathrm{S}_{11}$ of the slotted patch antenna with the Feedback Antenna Lab 57-200, which can measure the $S_{11}$ parameter in the band of 1200-1800MHz. We note that the measured and simulated $S_{11}$ of the antenna are nearly the same, even if we observe that there is a small instability in the measured $S_{11}$ due to the measurement environment (fig9). 
International Journal of Advanced Research in Electrical, Electronics and Instrumentation Engineering (An ISO 3297: 2007 Certified Organization)

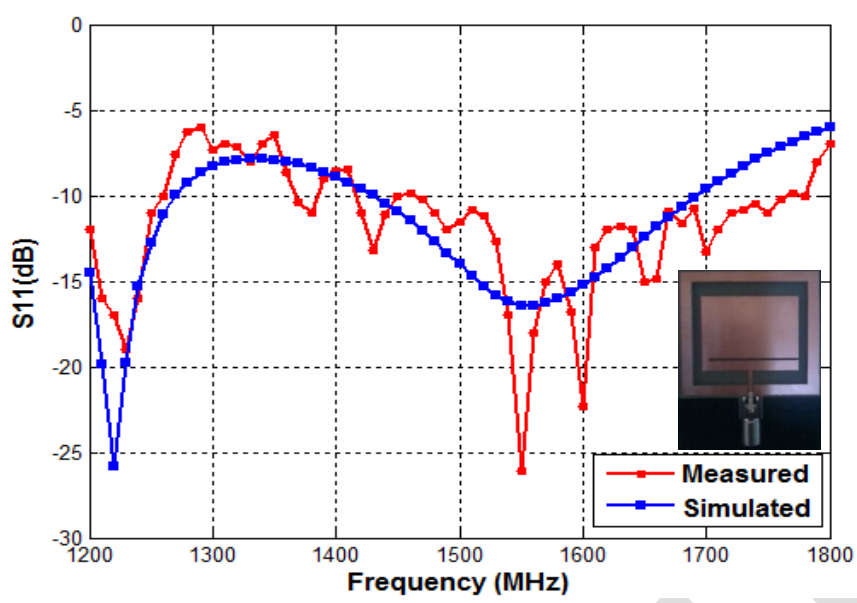

Fig. 9 Simulated and measured $S_{11}$ versus frequency of the antenna with the slot

Also, the simulated maximum total gain of the antenna varies between $0.2 \mathrm{~dB}$ and $2.9 \mathrm{~dB}$ in the band of $1200-1800 \mathrm{MHz}$ (Fig10).

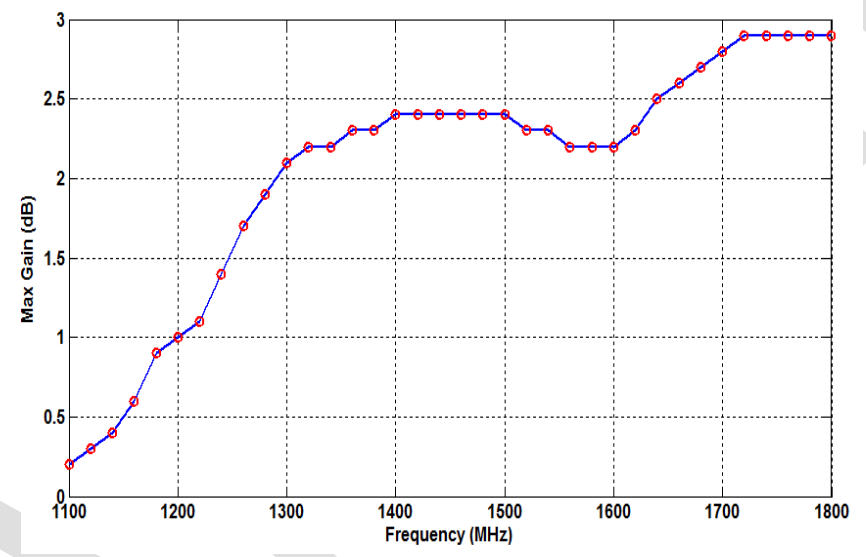

Fig.10 Simulated maximum gain versus the frequency of the antenna with the slot

We observe also that the simulated 3D total gain of the antenna is bi-directional (Fig11)

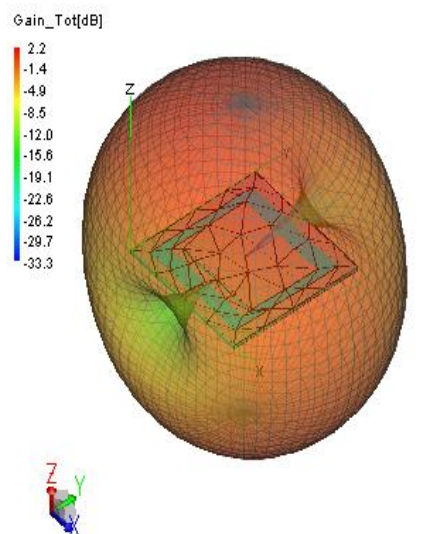

Fig.11 Simulated 3D gain of the antenna with the slot for the frequency (L1:1575MHz) 


\section{Vol. 3, Issue 8, August 2014}

\section{CONCLUSION}

A dual-band rectangular CPW folded slot antenna is simulated with "FEKO 6.3" and measured by "FeedBack Antenna Lab 52-200".

The antenna operates for all the bands of the GNSS Systems (L1-L2-L5-E5-E6-G1-G2) and its maximum gain varies between $0.2 \mathrm{~dB}$ and $2.9 \mathrm{~dB}$ in the band of $1200-1800 \mathrm{MHz}$.

Also, further refinement can be done to improve the gain and to miniaturize the antenna.

\section{REFERENCES}

[1] P.MisraandP.Enge, Global Positioning System: Signals, Measurements, and Performance. Lincoln, MA, USA: Ganga-Jamuna Press, 2010.

[2] N. Samama, Global Positioning: Technologies and Performance. New York, NY, USA: Wiley, 2008.

[3] Jean-Marc Piéplu, GPS et Galileo: Systèmes de positionnement par satellites, Eyrolles, ISBN : 978-2-212-11947-3, 2006

[4] FEKO 6.3 User's Manual,' EM Software \& Systems-S. A, October 013, pp.1-1.

[5] Ahmad A. Gheethan and Dimitris E. Anagnstou, "Broadband and Dual-Band Coplanar Folded-Slot Antennas (CFSAs) " IEEE Antennas and Propagation Magazine, Vol. 53, No.1, pp 80-89, February 2011.

[6] Long Zheng, and Guangming Wang, "DESIGN OF TRIPLE-FREQUENCY FOLDED SLOT ANTENNA FOR 2.4/3.5/5.2/5.8-GHz WLAN APPLICATIONS", Progress In Electromagnetics Research Letters, Vol. 43, pp115-123, 2013

[7] K. F. Lee, S. L. S. Yang, and A. A. Kishk, "Dual- and multiband U-slotpatch antennas,” IEEE Antennas Wireless Propag. Lett., vol. 7, pp. 645$647,2008$.

[8] C. Hsieh, T. Chiu, and C. Lai, "Compact dual-band slot antenna at the corner of the ground plane," IEEE Trans. Antennas Propag., vol. 57, no. 10, pt. 2, pp. 3423-3426, Oct. 2009.

[9] Peng Gao, Shuang He, Xubo Wei, Ziqiang Xu, Ning Wang, and Yi Zheng, "Compact Printed UWB Diversity Slot Antenna With 5.5-GHz Band-Notched Characteristics", IEEE Antennas and Wireless Propagation Letters, Vol. 13, 2014, pp 376-379

[10] A. Reha and A. Oulad Said, "Tri-Band Fractal Antennas for RFID Applications," Wireless Engineering and Technology, Vol. 4 No. 4, 2013, pp. 171-176. doi: 10.4236/wet.2013.44025.

[11] A. Mak, C. R. Rowell, R. D. Murch, and M. Chi-Lun, “Compact multiband planar antenna for 2.4/3.5/5.2/5.8-GHz wireless applications,” IEEE Antennas Wireless Propag. Lett., vol. 11, pp. 144-147, 2012.

[12] D. C. Chang, B. H. Zeng, and J. Liu, “CPW-fed circular fractal slot antenna design for dual-band applications,” IEEE Trans. Antennas Propag., vol. 56, no. 12, pp. 3630-3637, Dec. 2008

[13] Bala, B.D. ; Rahim, M.K.A. ; Murad, N.A. ; Ismail, M.F. ;Majid, H.A., Design and Analysis of Metamaterial Antenna Using Triangular Resonator, Microwave Conference Proceedings (APMC), 2012 Asia-Pacific

[14] Ming Chen, Chi-Chih Chen, A Compact Dual-Band GPS Antenna Design, IEEE ANTENNAS AND WIRELESS PROPAGATION LETTERS, pages 245-248, VOL. 12, 2013

[15] Constantine A. Balanis, Antenna Theory - Analysis and Design, A JOHN WILEY \& SONS, INC. PUBLICATION, 2005. 